Review

\title{
Power Quality in DC Power Distribution Systems and Microgrids
}

\author{
Stephen Whaite ${ }^{1,2, \dagger}$, Brandon Grainger ${ }^{1,2, \dagger}$ and Alexis Kwasinski ${ }^{1,2, *}$
}

1 The Center for Energy, Swanson School of Engineering, University of Pittsburgh, Pittsburgh, PA 15261, USA; E-Mails: smw72@pitt.edu (S.W.); bmg10@pitt.edu (B.G.)

2 The Department of Electrical and Computer Engineering, Swanson School of Engineering, University of Pittsburgh, Pittsburgh, PA 15261, USA

$\dagger$ These authors contributed equally to this work.

* Author to whom correspondence should be addressed; E-Mail: akwasins@pitt.edu; Tel.: +1-412-624-8000; Fax: +1-412-624-8003.

Academic Editor: Josep M. Guerrero

Received: 15 March 2015 / Accepted: 8 May 2015 / Published: 15 May 2015

\begin{abstract}
This review paper discusses power quality considerations for direct current (DC) electric power distribution systems, particularly DC microgrids. First, four selected sample DC architectures are discussed to provide motivation for the consideration of power quality in DC systems. Second, a brief overview of power quality challenges in conventional alternating current (AC) distribution systems is given to establish the field of power quality. Finally, a survey of literature addressing power quality issues in DC systems is presented, and necessary power quality considerations in DC distribution system design and operation are discussed.
\end{abstract}

Keywords: power quality; DC distribution; DC microgrid; inrush current; grounding; DC architectures; datacenter; residential power systems; telecommunication power management

\section{Introduction}

Direct current (DC) architectures for electric power distribution systems and microgrids have been increasingly explored with the goals of more efficiently serving most modern loads that require DC power and, thus, need to have alternating current (AC) to DC conversion stages when powered from conventional power distribution grids [1]. Additionally, DC power distribution systems allow for more 
efficient integration of energy storage and distributed renewable generation through the elimination of some rectification and inversion power electronics converter stages [1]. DC architectures have been explored for data center applications with the goal of increasing efficiency, in part by eliminating the need for an inverter on the UPS end of the power distribution path and the rectifier on the load end of the power path [2,3]. In commercial or residential buildings, the use of DC distribution architectures is proposed in literature to increase efficiency by allowing the use of larger and more efficient centralized distribution rectification stages rather than individual point-of-load rectifiers for the loads requiring DC [4-6]. Other proposed applications for DC architectures are for microgrid applications to more efficiently integrate energy storage and distributed renewable generation that produce DC voltage, such as in suggested cellular communication microgrids $[7,8]$.

An important consideration in the design of both AC and DC distribution systems is that of power quality. Power quality generally refers to the voltage quality on a power system; however, the voltage signals are not independent of the current signals. Hence, the study of power quality necessarily involves the study of voltage and current together. The two primary impacts of power quality issues on a distribution system are the potential for equipment operation to be adversely affected by a power quality problem and the reduction in power factor caused by certain types of harmonics. An end-user centric definition for "power quality problem" has been proposed by the Electric Power Research Institute (EPRI) to be "Any power problem manifested in voltage, current, or frequency deviations that results in the failure or misoperation of customer equipment" [9]. A definition for true power factor is provided by the Institute of Electrical and Electronics Engineers (IEEE) to be "The ratio of the total power input, in watts, to the total volt-ampere input" and includes both the effects of traditionally considered phase displacement power factor and distortion power factor [10]. Power quality considerations are well documented and studied on AC power systems, but many power quality questions have yet to be definitively addressed or studied for DC distribution systems.

Power quality issues and, in particular, electromagnetic interference (EMI) caused in most cases by power electronic devices, has also been extensively studied in mobile power distribution systems for transportation applications, such as electric ships [11-13], airplanes [14], and electric vehicles [15,16]. However, in most of these cases, power quality and EMI issues are addressed primarily through ad-hoc approaches usually based on filters or enhanced cable shielding. As indicated in [17], power quality issues and solutions found in mobile power distribution systems cannot be necessarily directly applied in general to stationary applications that are the focus of this paper because of technical and commercial issues (e.g., different grounding and dissimilar cost requirements). Hence, although many of the power quality issues that apply to mobile power distribution systems are still discussed in this paper, the discussion here focuses on stationary systems and applied on a general context instead on considering the particular conditions found in mobile applications.

In this paper, the current literature addressing the power quality issues for DC distribution systems is surveyed. The organization of the paper is as follows: in Section 2, four sample architectures that have been proposed as opportunities to use DC architectures to increase efficiency, sustainability, or availability are discussed to motivate the discussion of DC distribution systems. In Section 3, a brief overview of power quality considerations in AC distribution systems is given. In Section 4, power quality considerations identified as important to the consideration and design of DC distribution 
systems are discussed. Section 5 gives conclusions and summarizes the power quality issues that must be considered in the design of a DC distribution system.

\section{Sample DC Architectures}

\subsection{Data Center Challenges and Approaches towards Improved System Efficiency}

As the world becomes increasingly dependent on digital information systems, there has been growth in the number and size of data centers. All power consumed globally by data centers in 2010 was between $1.1 \%$ and $1.5 \%$ of total electrical energy consumption, and in the United States alone, data centers require between $1.7 \%$ and $2.2 \%$ of total generated electrical power $[18,19]$. With continued growth and use of information technology devices, methods of improving data center efficiency through more resourceful electrical architectural design should be critically evaluated.

Data centers are facilities containing IT equipment used for data processing like servers, storage components, and networking devices. Power distributed through the data center to this equipment is converted at various voltage levels from entrance to the computer loads. These levels include the building-level supply (typically $480 \mathrm{Vac}$ in the United States), backup-level where uninterruptible power supplies and fuel-driven generators are used to provide power if building-level power is temporarily unavailable, rack-level where power (208 Vac rating) feeds DC power converters, board-level where DC power feeds server boxes, and finally chip-level (typically three to five different voltage levels) where point of load DC/DC converters condition power for the chip sets [20].

\subsubsection{State of the Art Data Center Architecture Design for Improved Efficiency}

DC systems have been shown to enable a simpler integration of energy storage devices to meet both energy and power buffer needs. More importantly, the experience of the telecommunications industry with using both AC and DC systems seems to indicate that well-designed DC systems can provide superior reliability than AC system designs [21]. Also, integrating multiple sources into a DC system has advantage of not requiring frequency control and phase synchronization; $\mathrm{AC}$ architectures require sources to be synchronized, adding another layer of control complexity. However, DC systems can present stability challenges because of the nonlinear dynamics of the power electronic converters used to create the DC voltage; point of load converters interfacing IT equipment, as in Figure 1, act as constant power loads that introduce destabilizing effects in the network [22]. Lastly, DC architectures must deal with detecting and clearing faults on the DC bus, as will be discussed further in Section 4 of this paper.

Microgrid research has been primarily dedicated to the study of power converters that connect distribution generation resources through means of a single input or multiple input interfaces [21]. As pointed out by [23], data centers can be integrated into a DC microgrid type configuration to meet the required reliability metrics and possibility reduce loss. Figure 2 provides two approaches for integrating data centers in a DC environment. The left architecture eliminates the need for the diesel generator to synchronize with the AC grid, while the right has improved efficiency with fewer power conversions between the generator and the HVAC system. Additionally, the configuration on the right has better availability as the HVAC equipment can also be powered when a diesel generator failure 
follows a power grid outage [24]. However, this configuration requires additional batteries for an equivalent IT configuration and target availability.

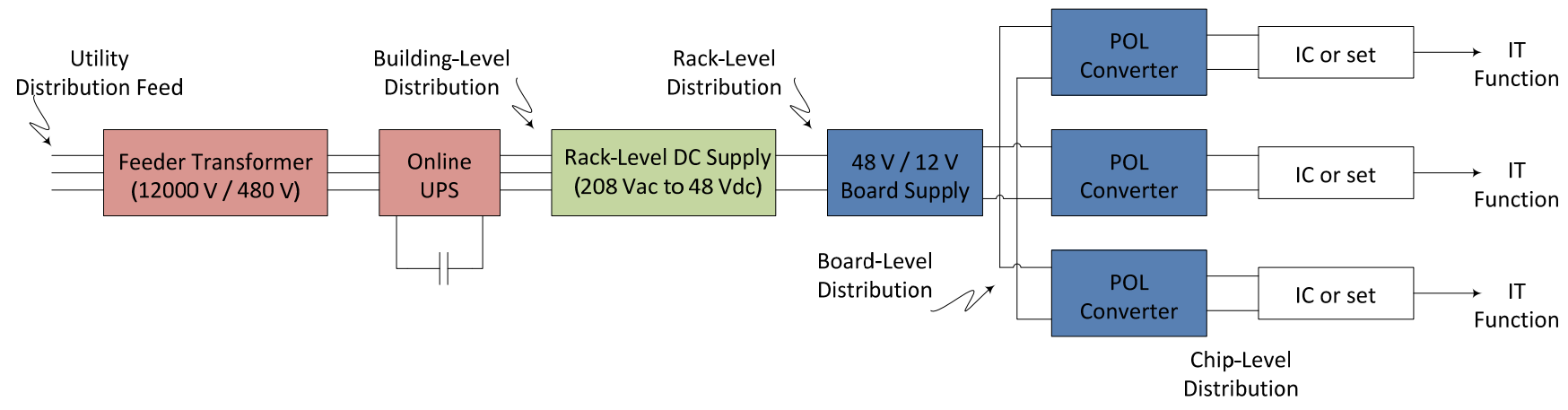

Figure 1. Typical AC data center layout emphasizing power distribution voltage levels [13].
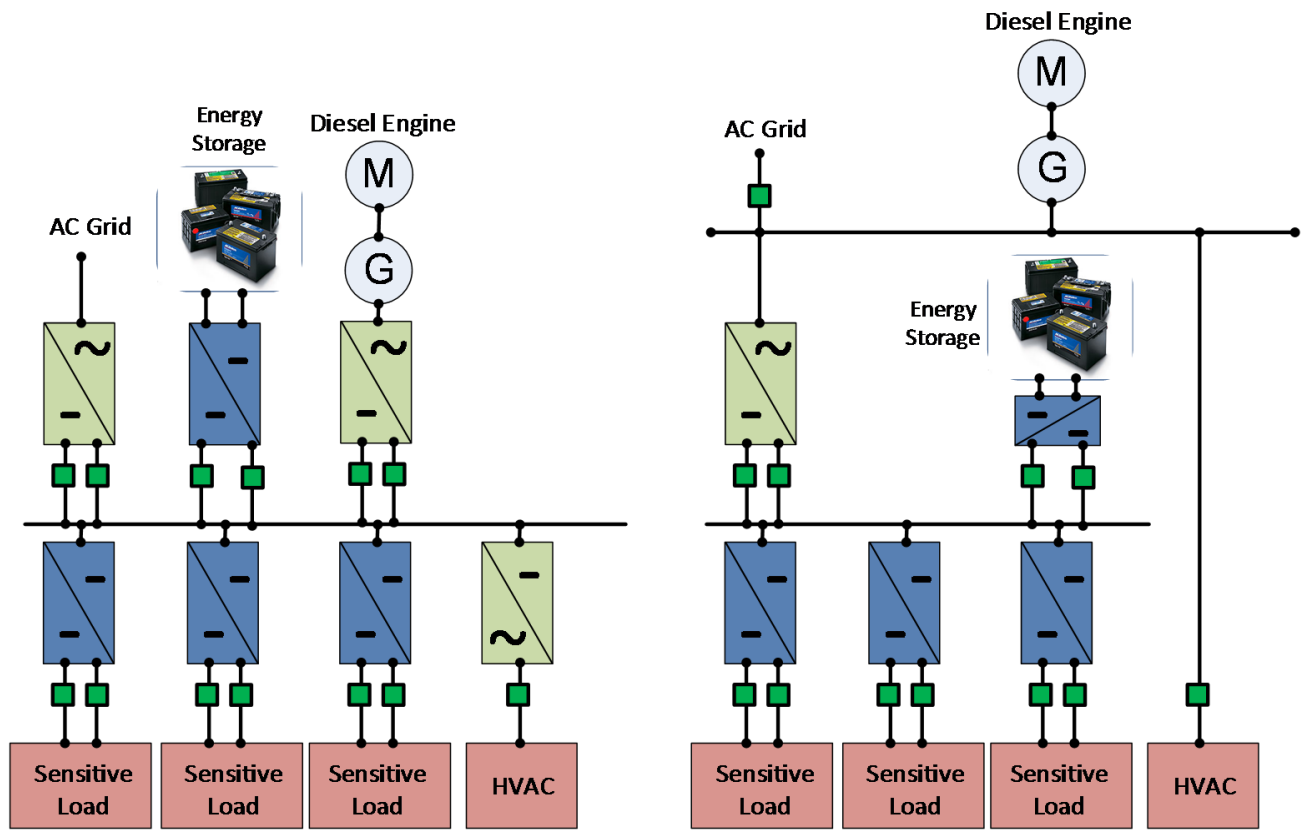

Figure 2. Two Options for Data Center Components implemented in a DC Microgrid [16].

The percentage of the power consumed by an AC data center distribution system actually used by the IT loads is below 50\% [25] as most of the energy inefficiencies in data center originate in thermal issues, such as inefficient air circulation or heat transfer [24]. Many cascaded power conversion stages in series-Each stage causing some drop in efficiency with the total efficiency equaling the product of the individual efficiencies of each stage-And more power required for cooling systems to remove the heat dissipated at each stage are the main reasons for poor power utilization. Although the architecture of Figure 1 is well accepted by the community, and the architectures in Figure 2 are newer approaches each utilizing a DC bus, large converter size is a current issue in data center distribution architectures. As an example, consider the rack level power supplies in Figure 1. These converters have to perform a large voltage step down and process the full server power. Methods have been investigated by research teams to avoid high conversion ratios at various stages but accurate voltage regulation between stages can be compromised [19]. Recent approaches in academia for improving data center efficiency have investigated power converter efficiency improvements by using hardware approaches with wide 
bandgap power devices, [25], or sophisticated controllers that actively regulate individual server voltages with differential power processing techniques, $[19,26]$.

Despite the difficulties mentioned, Intel Corporation has done a thorough analysis of several power delivery architectures and concluded that utilizing a facility-level $400 \mathrm{~V}$ DC-based power distribution architecture may be the best option to date and quantified the end-to-end efficiency to be close to $73 \%$ [27]. Many of the reported power delivery voltage values and the associated system efficiency are provided in Figure 3 below.

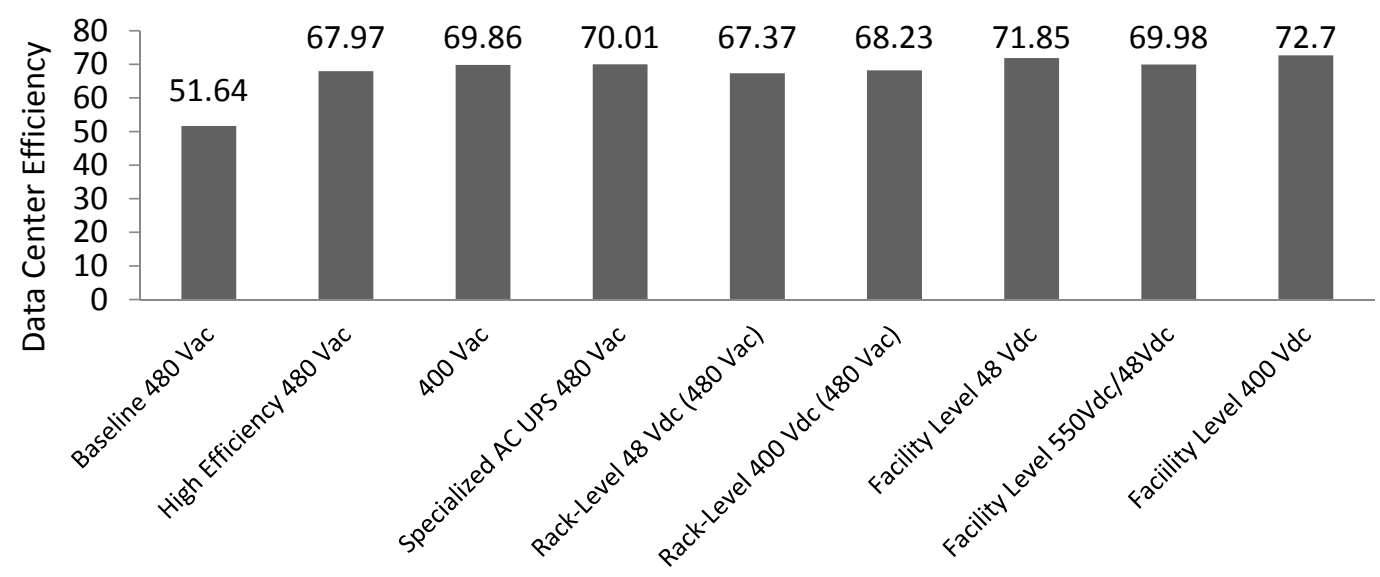

Figure 3. Total Data Center Efficiency as a Function of Supply Voltage [27].

\subsubsection{Worldwide DC Data Center Installations and the Need for Standardization}

In 2007 a workshop was sponsored by Intel Corporation in Santa Barbara, California (USA) focusing on approaches for improving data center efficiency. Varied recommendations for DC voltage levels were proposed, with some groups suggesting the use of $550 \mathrm{Vdc}$ supply [28], while $300 \mathrm{Vdc}$ was suggested by attendees from Japan and $350 \mathrm{Vdc}$ by attendees from Sweden [29]. $380 \mathrm{Vdc}$ was suggested for power distribution in United States data centers [29]. These wildly varied voltages are partly influenced by the different AC building distribution voltages used around the world, but, as a result of this workshop, the data center community recognized the need for global acceptance on a unified voltage.

Globally, the data center market is beginning to standardize their systems around two voltages: $380 \mathrm{Vdc}$ and $400 \mathrm{Vdc}$. Conventional supply voltages of $48 \mathrm{Vdc}$ power supply systems have been the worldwide standard for the last century [29]. With extensive studies done by Lawrence Berkeley National Laboratory with Intel Corporation, $380 \mathrm{Vdc}$ begins to gain traction and further investigation has been made by other teams including NTT Facilities, Inc., based out of Tokyo, Japan [29,30]. Currently, there are 23 worldwide installations rated for higher power at $380 \mathrm{Vdc}$ [29].

Advantages of using $380 \mathrm{Vdc}$ are reported in [31]. Notable advantages, besides efficiency improvement, include a $15 \%$ less up-front capital cost, 33\% less floor space, $36 \%$ lower lifetime cost, and 20 to 100 times less copper for converters compared to $48 \mathrm{Vdc}$. For these reasons, international standardization around $380 \mathrm{Vdc}$ has begun since 2009 through the International Electrotechnical Commission (IEC), European Telecommunication Standards Institute (ETSI), and International Telecommunication Standardization Sector (ITU-T). Within the Institute of Electrical and Electronics 
Engineers (IEEE), the Power Electronics Society (PELS) has established a $380 \mathrm{Vdc}$ working group and the Power and Energy Society (PES) has begun DC standardization efforts for the future DC home. The motivation to consider of $380 \mathrm{Vdc}$ within homes comes as a result of developments within the electric vehicle and stationary battery markets [29].

\subsection{The Role of DC Microgrids within Commercial Facilities and Residential Homes}

DC distribution for residential applications is also becoming a research focus in the literature, motivated by both global renewable energy targets (for example solar coupled with battery storage) and widespread adoption and use of residential loads that convert to DC before end-use (computer equipment, modern televisions, and standard home appliances). A common theme in literature comparing $\mathrm{AC}$ and DC based distribution is promoting fewer power conversions as being a primary advantage of DC over AC design [32,33]. Presently, 30\% of all electric power generated uses power electronics technologies somewhere between the point of generation and end-use, and by $2030,80 \%$ of all electric power is expected to flow through power electronics [34]. The need to understand how power electronics equipment in the grid responds to, interacts with, and delivers power to changing loads in commercial and residential installations due to operational mode transitions is a valuable exploratory effort because this will be a future scenario that will need to be handled appropriately both in AC and DC systems. To date, relatively few research efforts have focused on DC power distribution for residential applications like single-family houses [32].

\subsubsection{Voltage Selection for Home Appliances and Lighting Systems within DC Homes}

To date relatively little attention has been focused on optimizing electrical loads in residential homes, even though $37 \%$ of all electrical energy delivered by U.S. utilities is consumed by residential buildings [35]. Two proposed DC microgrids are shown for DC homes and lighting in Figure 4. To establish voltage standards for energy savings and safety, three criteria are addressed that include line thermal limits, voltage drops, and power losses.

Appliances in the kitchen tend to be higher in power consumption than other many other appliances used in the home, many of which can be modeled as resistive loads and supplied with DC directly [36]. Other appliances that are non-resistive loads, such as microwave ovens, dishwashers, and refrigerators, can be energized with DC if these components are interfaced with inverters. Arguments in [32] have suggested the use of $120 \mathrm{Vdc}$ for kitchens and air conditioning to achieve lower copper losses and wire costs.

A DC lighting system designed in [37] is shown in Figure 4b. Two distinct systems are shown. The DC side is supported by a $380 \mathrm{Vdc}$ bus and the AC side (strictly developed for comparison to the DC distribution architecture) is supplied by 230 Vac. The DC side of the system is entirely supplied by $2 \mathrm{~kW}$ of solar generation and the main load is $54 \mathrm{LED}$ down lights rated for $37 \mathrm{~W}$ each resulting in $2 \mathrm{~kW}$ of lighting load. AC grid power is rectified through the central rectifier to the lighting load as well. The AC architecture was designed to have equivalent generation and lighting loading as the DC architecture. One observation from this study is that comparable power electronic efficiencies can be observed between both systems, however, one advantage to the DC layout is the lower conversion ratio between voltages. 


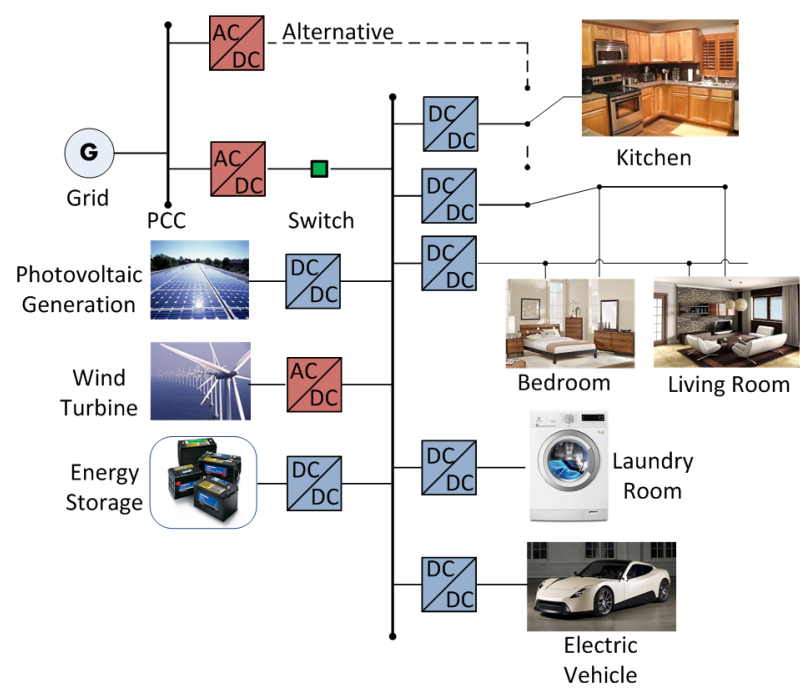

(a)

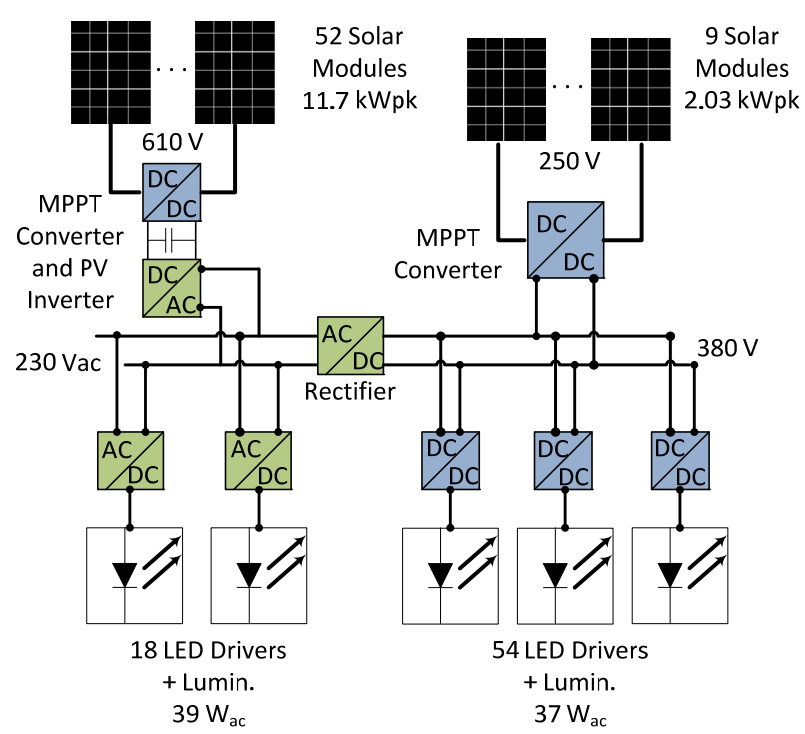

(b)

Figure 4. DC Microgrid architecture for (a) residential home [23] (b) home lighting system [28].

Regarding economics of these lighting systems coupled with solar generation [36] and [38] have shown that without the use of solar or energy storage, DC designs are slightly more expensive in comparison to $\mathrm{AC}$ systems. The economics are application specific because a DC zone within an electric ship provides electrical isolation, reduced cost, and increased stability in comparison to $\mathrm{AC}$ [39]. In summary, a detailed study of the relative costs and benefits will be needed to determine which DC or AC architecture is most economically optimal for each individual applications.

\subsubsection{Power Electronic Systems and their Potential Role in Building-Side DC Circuit Breaker Panels}

When investigating the development of a next generation microgrid, it is important to explore what type of interfacing mechanisms will exist between the main AC grid and the loads that it will be serving. With many global research efforts focusing on DC microgrids [40,41], development of high power topologies for DC-DC converters to serve as the interfacing entity between grid and load still requires increased investigation. In particular, novel applications of multiple input multiple output (MIMO) converters have been suggested to achieve a good compromise between high availability and reduced costs [21]. When working with conventional DC converter designs such as the buck, boost, buck-boost, SEPIC, and Cuk converters, a few guidelines have been suggested to assist the development of multiple-input converters with an emphasis placed upon minimizing the number of components used while still maintaining desirable operation. Guidelines for feasible multiple-input DC-DC converters are provided in literature [42].

As such, the following converter features are important for achieving advanced grid power management:

- Achieve bidirectional operation to allow for both traditional power flow from the grid to the home as well as on-site (home-side) renewable generation and energy storage to flow back into the microgrid.

- Provide dynamic protection between the grid and the home from transient electrical phenomenon such as lightning strikes or equipment surges. Currently an isolation stage is mandatory in the United States when interfacing with a power grid with converters as indicated in the National 
Electric Code so there must be either a low frequency transformer at the input of the PCC between the grid and the microgrid or a high frequency transformer in the converter itself.

- Have the capability to perform as a single-input, multiple-output device with a single $380 \mathrm{~V}$ connection to the microgrid DC Bus and two building-side voltages of $24 \mathrm{~V}$ [37] and $48 \mathrm{~V}$. A circuit topology to perform these transformations is shown in [43]. These voltage transformations should be accomplished with minimized number and size of magnetic components. For example, new converter topologies have been proposed in the literature using higher frequency switching to reduce transformer size [44].

Homeowners are well accustomed to their AC circuit breaker panel with the capability of energizing/de-energizing feeders throughout their home on demand. AC circuit breakers have a distinct advantage over DC circuit breakers when it comes to extinguishing current since AC signals naturally cross zero 120 times per second. These repeated zero-crossings degrade the electrical arc that forms when tripped breaker contacts separate.

For the case of a DC based home having continuously (never zero crossing) energized feeders due to DC current distribution, future DC homeowners would not be able to simply enter the panel and simply open or close feeds mechanically at will. Because DC signals do not cross zero unless otherwise forced, either the designed breaker must operate faster with the contacts separating much further than their AC counterparts, or modified designs must be used for the breaking mechanism in order to force the current towards zero.

With this generic problem identified, one critical advantage associated with the bidirectional circuit topology is its capability to minimize power flow from input to output if desired with appropriate control settings within DC environments [45]. Consider the standard panel found in homes or other industrial settings found in Figure 5.
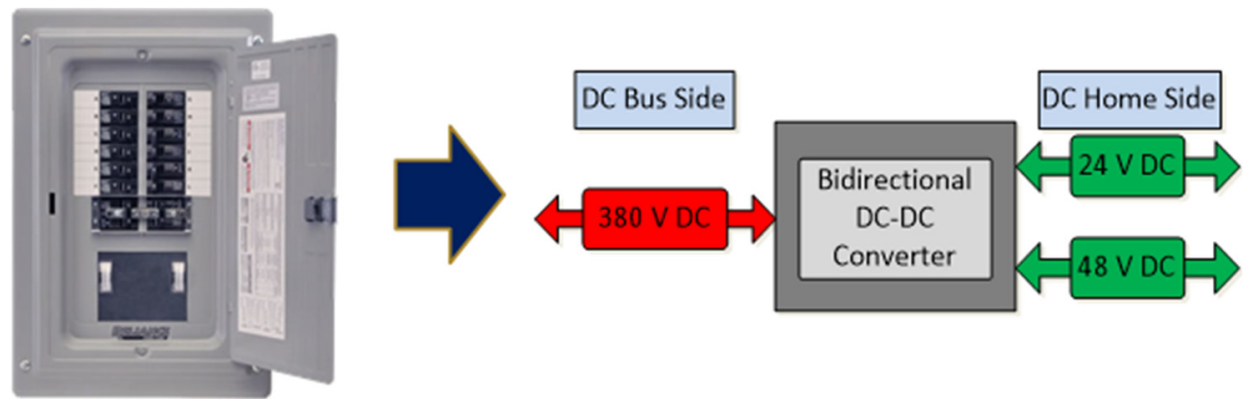

Figure 5. Traditional AC breaker panel (left) and Single Input, Multiple Output Bidirectional DC/DC converter equivalent (right).

Next imagine a single input-dual output (for illustrative purposes) DC-DC converter topology with bidirectional capability serving as the building block mechanism mounted within future DC panels used to interrupt current flow. Ideally, a touch screen interface would be mounted on the outside of the panel so users could: (1) trigger the converter to adjust its settings so current would cease and (2), once current is diminished, trigger mechanical contacts to open feeders without the homeowner ever entering the DC panel. This concept is conceptual with the intent of presenting the concept to the engineering community because this will need to be addressed for sure by future research groups focused on DC homes. 


\subsection{DC in Telecommunications Power Systems}

DC power distribution has been traditionally used for many decades in telecommunication power systems. The most commonly used voltage level in communication systems has been $-48 \mathrm{~V}$ originally used in wire-line systems. Although this voltage was chosen because it ensured that voltages at customer premises would remain below the $60 \mathrm{~V}$ safety limit, this voltage has also been in wireless communication systems. However, other voltages has also been used in the past, such as $140 \mathrm{~V}$ for toll central offices in the U.S. or $24 \mathrm{~V}$ in CDMA base stations. Outside plant electronic equipment is currently also being powered by a split-phase $\pm 190 \mathrm{~V}$ dc power distribution system [46].

In term of power quality, most of the focus in communication systems is to ensure adequate voltage drops in the local loop or in loads that ensures adequate signal quality. Due to the presence of batteries directed connected to the dc system bus, most power quality issues in communication facilities are reduced. Although the presence of constant-power loads may create some issues, in addition to voltage drops, typical power quality concerns in telecommunication facilities are momentarily voltage disruptions due to short circuits or inrush currents. These voltage disruptions are typically filtered with capacitors in main distribution frames located closed to the electronic loads. Surge protectors are also used to limit the effect of lightning strikes or other discharges in the local loop or other exposed circuits, such as grid tie or antenna feeds. In all facilities, good grounding practices are essential in order to ensure adequate power quality levels.

More recently, the search for solutions for an increased use of renewable sources in wireless communication networks has led to the proposal of using dc microgrids that create a so-called sustainable wireless area (SWA) by electrically interconnecting a few cell sites in a dc microgrid operating at, for example, $380 \mathrm{~V}$, in which power generation, energy storage levels and loads (i.e., base stations traffic) are managed in an integrated way [7,8,47]. This goal of increased use of renewable sources in wireless networks is motivated by the goals of achieving more sustainable and resilient wireless communication networks by addressing the most important limitations found in photovoltaic and wind generation systems: Large footprint and variable output. These issues limit the use of renewable sources for powering individual cell sites particularly in urban and suburban locations where space is limited. Although the proposed approach of developing SWAs address these limitations it also present some power quality challenges. These challenges originate in the different power architecture observed in SWA in which batteries may not be necessarily located at each cell site. As a result, power quality issues may be easier to observe in cell sites without batteries because there may be longer distances between batteries and communication equipment that would reduce the effectiveness of batteries directly connected to a main bus near the load in order to mitigate potential momentary voltage disruptions. Approaches for addressing these power quality issues are currently under study, highlighting the importance of identifying power quality issues and characteristics in microgrids.

\subsection{Transmission Level DC Grid Applications}

Renewable power distribution methods for wind farms and solar panel fields have traditionally been based upon $\mathrm{AC}$ system design using large transformers to alter system voltages at various points 
throughout the system circuit. Investigating the application of medium voltage DC (MVDC) collection systems for larger installations of renewable energy resources is being considered by researchers, globally.

One focus has been with the design of higher power DC/DC converters-Acting as a type of DC transformer-For these MVDC collection systems as in [48] and [49]. Although MVDC collection systems currently do not exist, [49], reference [48] provides a set of electrical architectures envisioned for integrating multiple wind turbines. These architectures are provided in Figure 6 and can be adapted for photovoltaic panels.

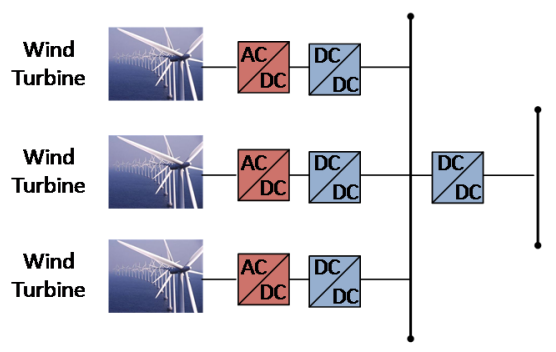

(A)

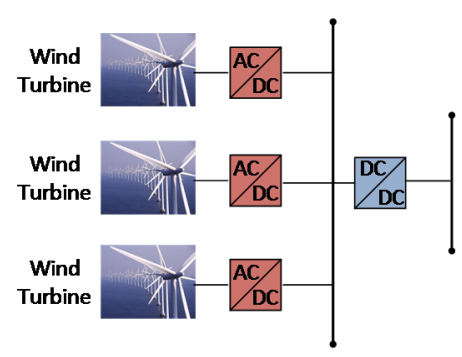

(B)

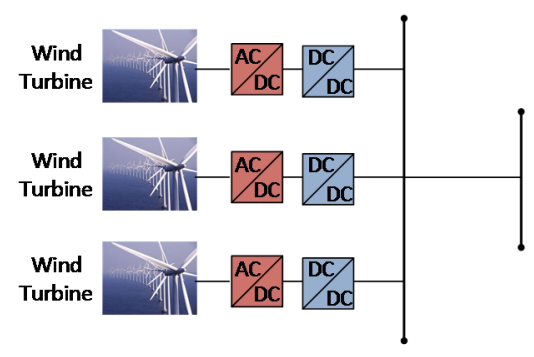

(C)

Figure 6. Different configurations for integrating wind turbines (or solar systems) into a

DC grid. (A) Two step-up conversions. (B) Centralized step-up. (C) Turbine power step-up.

Each of the collector architectures has distinct advantages and disadvantages. Collector (A), in Figure 6, has the advantage of using low voltage output turbines. The output voltage can also be controlled individually. But, with more power conversion stages, this system results in lower efficiency and increased cost. Collector (B) provides the advantage of using fewer converters and, therefore, less power electronic components. Because fewer components at each wind turbine are used with this configuration, maintenance at each wind turbine is minimized and is mainly needed at the collection point. The drawback of this configuration is that medium voltage turbines must be used because rectifiers are only present to boost voltage at the point of common coupling for the collection system. Finally, collector (C) is essentially a hybrid of collectors (A) and (B) whose losses are about half of those of Collector (A) but twice of collector (B) [48].

\section{AC Power Quality}

In AC distribution systems, power quality concerns are well studied and are addressed by standards from both the IEC and the IEEE. In the IEEE Standards Association guide on voltage quality concerns in power systems, power quality issues are divided into steady-state voltage quality characteristics and disturbances [50]. Beginning in 1989 and continuing through the 1990s, EPRI began a study of power quality on U.S. electric utility distribution systems, the results of which provide insight into the range and frequency of power quality concerns for a utility customers on AC distribution architectures [51]. Poor power quality can prove problematic for sensitive industrial equipment or electronic loads, and so many customers seek premium power quality either through voltage conditioners or full storage and distributed energy reinforced AC microgrid solutions [52,53]. 


\subsection{Harmonics}

Harmonic voltage distortion on AC distribution systems is a continuously observed condition due to the presence of nonlinear loads - That is, harmonic distortion is not merely a momentary transient condition of a power system, but continues until the nonlinear loading effect is removed or the harmonics are otherwise compensated for. Nonlinear loads draw current that is not sinusoidal in response to sinusoidal voltage and typically include nonlinear loads include variable frequency drives (VFDs), switching power supplies, fluorescent lighting ballasts, battery chargers, saturated transformers, and arc furnaces [9]. Many of the listed loads cause nonlinear loading effects by the use of power electronic converters. Harmonic current is of concern because of the potential to cause voltage distortion through voltage drop over line impedances, increase losses in transformers, and originate resonance interactions with capacitance on the system in the form of capacitor banks or insulated cables [10].

In addition, the harmonics caused by non-linear loads can also reduce the true power factor substantially [54]. The reduction of true power factor occurs even when displacement power factor is close to unity, and the total harmonic distortion (THD) caused by a load gives a maximum achievable true power factor [55]. As stated in the introduction, the definition of true power factor is given by the IEEE to be the ratio of total real power input to the total apparent power input in volt-amperes [10]:

$$
p f_{\text {true }}=\frac{P_{\text {avg }}}{V_{r m s} I_{r m s}}
$$

Passive or active harmonic filters can be used to compensate for excessive levels of harmonic currents by an customer, as limits for harmonic current are often imposed by utilities based on requirements proposed in standards such as IEEE 519 [10]. In addition, flexible control of the power electronic converters that are the source of harmonic current effects is being researched as a method to limit harmonics [56].

\subsection{Disturbances}

Disturbance related power quality problems on a distribution system include momentary voltage transients, sags, and interruptions. These disturbances often fall outside the realm of traditional reliability metrics used by utilities, which use outage frequency and duration and do not take momentary disturbances into account, however disturbances can create problems for the operation of sensitive loads [57].

The causes of disturbances are varied in power systems. Voltage transients are often caused by switching events on a power system such as capacitor or reactor bank switching or transmission line switching. Voltage sags on a distribution system are typically due to a fault either within the customer facility or on the utility system, though inrush currents to large motor loads can also cause voltage sags [57].

Customers with sensitive loads have a number of options to compensate for disturbance related power quality problems. One of the observed solutions is an uninterruptible power supply (UPS), particularly an on-line UPS which provides power to the load through a rectifier and inverter and includes energy storage on the DC link [50]. On-line UPS systems protect against both momentary 
disturbances and short-duration outages but are costly. More affordable methods to compensate for voltage transients and sags include the use of a power electronics or transformer-based voltage conditioner, while protection from surges is generally provided by surge suppressors [50].

\section{Power Quality in DC Distribution Systems and Microgrids}

The power quality concerns of DC distribution systems or microgrids are different in many ways from those in grid-connected $\mathrm{AC}$ distribution systems. The alleviation of some common $\mathrm{AC}$ harmonic issues is sometimes even given as a motivation for pursuing DC architectures [41]. The differences between the study of power quality in AC distribution systems and the study of power quality in a DC distribution system come both from difference between the ideally constant voltage in a DC system and the alternating sinusoidal voltage in an $\mathrm{AC}$ system and from the many power electronic converters that form the backbone of DC distribution system. The four fundamental DC distribution system power quality concerns identified in literature and discussed in this section are harmonic currents, inrush current, fault current, and grounding.

\subsection{Harmonic Currents}

As stated above, it is often claimed that DC systems do not experience harmonic currents or voltages. At a surface level, this is true by definition, since the fundamental frequency of a DC system is $0 \mathrm{~Hz}$ and integral multiple frequencies of $0 \mathrm{~Hz}$ other than the fundamental itself do not exist. At a practical level, however, the presence of current and voltage oscillations on a DC system similar to AC harmonics make the extension of the discussion of harmonics to DC systems relevant. For this reason, as in the references cited, the term "harmonic" will be used in this section to refer to both oscillatory voltages and currents on a DC system.

While transformer-fed AC distribution systems often have power electronic converters at the point of load (POL) that create harmonic currents or voltages on the system, DC distribution systems require converters both to connect the DC bus to an AC grid and at each point of connection to the DC bus for distributed generation with AC output, some cases of energy storage, and loads. Also, even energy storage or distributed generation that requires DC may use a bidirectional DC/DC converter to connect to the DC bus to allow independent control of the resource voltage and the bus voltage. The supply converters determine the voltage on the system, and converters and filters should be designed to minimize voltage oscillations and harmonics. Converter and filter design to minimize voltage oscillations under linear loads will not be addressed in detail here, as it is a fundamental concept in switching converters, and is addressed in a myriad of textbooks, research papers, and ongoing research. However, as the DC bus serves as a connection between multiple power electronic converters, current harmonics and circulating currents can arise on a DC bus from nonlinear effects of the various power electronic converters [58]. The importance of considering the impact of harmonic currents generated by nonlinear effects of power electronic converters is addressed in literature for both AC distribution systems and HVDC transmission systems. In HVDC system design, filters are required to mitigate the current harmonics or circulating currents which could cause electromagnetic interference (EMI) on equipment near the transmission lines and overloading and physical damage to the transmission system itself [59]. Similarly, in low voltage DC power systems, damaging resonance 
currents, unacceptable EMI, or problematic voltage oscillations can result from current harmonics on the DC bus, and a detailed harmonic study needs to be a consideration in the design of DC distribution systems [60]. In addition, even though DC systems intrinsically do not have a phase displacement power factor lower than unity, the true power factor is still reduced by harmonic distortion.

The methods for determining and analyzing harmonic currents in a DC distribution systems can be adapted from techniques used to study harmonics on the DC link between power electronics converters previously developed in depth in papers on AC-DC-AC converters for variable frequency drive applications [61-63].

In addition to harmonics on the $\mathrm{DC}$ bus itself, the harmonic current drawn from the AC utility grid at the point of common coupling (PCC) by the rectifier used to feed the DC distribution system is an important concern because of the potential to cause utility voltage harmonic distortion [64]. As mentioned in Section 3.1, many utility customers are responsible for adhering to harmonic current limits by requirements such as IEEE 519 [65].

\subsection{Inrush Current}

In AC distribution systems, inrush currents are typically associated with energizing a transformer or an induction motor, and these devices are not directly connected to the DC bus in a DC distribution system. Rather, power electronics converters interface the DC bus with loads, generation, and storage. To control the harmonic currents drawn by a load converter or the voltage ripple produced by a source converter, EMI filters are generally placed at the connection with the DC bus as shown in Figure 7, and the capacitance of these filters can draw substantial inrush current [66].

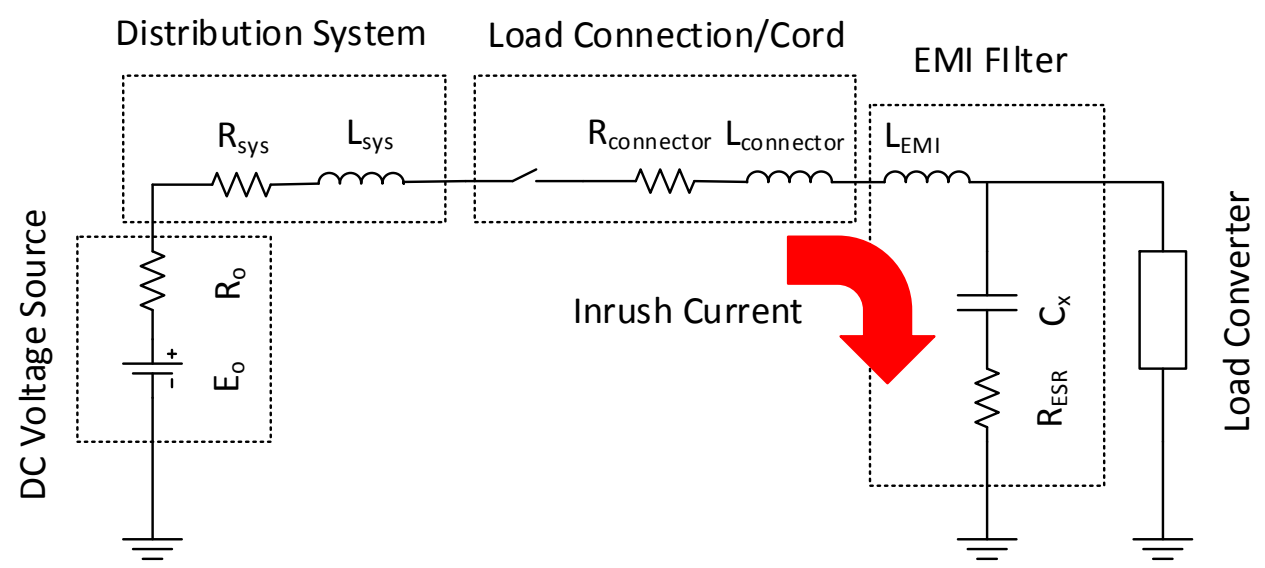

Figure 7. Sample DC distribution system with EMI filter for analysis of inrush current.

The converter capacitance, together with the voltage level of the DC system and bus, filter, and capacitor reactance and resistance, determine the inrush current magnitude and characteristics [67]. While smaller filter capacitances would reduce the inrush current, the minimum size of this capacitance is generally constrained during converter design by electromagnetic interference (EMI) standards the converter must meet.

When a de-energized load and its converter are switched into an energized circuit, an inrush current results due to the charging of the capacitance, regardless of whether the load is switched on or off [68]. This inrush current in DC distribution systems can be substantial enough to physically weld contact 
points together if connectors do not have sufficient tolerance, and the arc can cause other physical damage to the distribution system [69]. Even if the system is designed to withstand the resulting physical stresses, high inrush currents can cause voltage sags on the system that affect the operation of other equipment [67]. To address the issue of inrush current due to converter capacitance, pre-charge circuits or other soft-start methods are suggested [70].

\subsection{Fault Current}

The effects of faults on voltages around a power system is a well-defined field of study in AC power systems. In a strong AC system, a low source impedance allows the system to supply high fault current, minimizing the voltage effects at other points around the fault, while in a so-called weak AC system, high source impedance reduces the available fault current, and voltage is affected more by a fault. In a DC distribution system, however, a fault on the DC system can only draw fault current through converters or from energy resources or capacitance directly on the DC bus, and the fault current is limited by the power ratings of these converters and resources and the charge stored in the distributed capacitance in the buses of the circuit or connected capacitors [21].

While limited fault current does reduce the instantaneous stress placed on the power system, lower available fault current increases the voltage disturbance experienced during the fault at other points on the system [71]. In addition, faults are generally detected for protection purposes by relays that sense and respond to overcurrent measurements. If not enough fault current is available, it may be difficult to select protection settings that adequately differentiate between fault current and heavy load conditions [21]. To increase the available fault current, the capacitance on the EMI filters on the converters can be increased to store more charge, however increasing the size of the capacitance also increases the inrush current unless a pre-charge or soft-start method is used [72]. Furthermore, increasing the capacitance is significantly more costly at higher voltages.

In addition to the limited fault current available from converters and stored charge on the DC bus, DC distribution systems also suffer from the absence of periodic voltage and current zero-crossing points. In both series and parallel faults, this means an arcing fault does not extinguish as quickly in a DC system [73]. This is especially problematic for arcing open series faults in DC distribution systems, as series faults can develop a self-sustaining arc that is difficult to detect, since no current surge will occur [74]. Arcs present serious risk to both personnel and equipment through both electrical energy and the potential to start fires.

While circuit protection is not the focus of this review, it is important to note the substantial challenges in DC current interruption also caused by the absence of periodic current zero-crossings. AC circuit breakers are able to interrupt current by mechanically separating contacts and allowing the arc to extinguish at current zero-crossings. In contrast, interruption of direct current by mechanical separation is feasible only at lower voltage levels, and substantial open research into electronic methods of breaking DC current is being required. Protection in DC systems is receiving attention at both transmission voltages and distribution voltages [75]. A review of protection for DC distribution systems, particularly microgrids, has already been performed by Cuzner and Venkataramanan [76]. 


\subsection{Grounding}

As in AC distribution architectures, two main potential grounding configurations exist for distribution systems [2]. Grounding one of the poles to protective earth is termed TN-S grounding and is common in $\mathrm{AC}$ networks in buildings. In $48 \mathrm{~V} \mathrm{DC}$ power systems used for telecommunications, the positive pole is grounded and the system operates as a $-48 \mathrm{~V} / 0 \mathrm{~V}$ system. When considering higher DC voltages such as $380 \mathrm{~V}$ or $400 \mathrm{~V}$ for distribution, however, the IT grounding concept with high resistive mid-point connection to protective earth provides safety enhancements by limiting the potential ground current for a line-to-ground fault, as well as halving the voltage to ground on the system compared to the TN-S concept. The TN-S and IT grounding concepts for DC distribution systems are shown in Figure 8.

The choice of an appropriate grounding configuration for a DC distribution system has an impact on the power quality and safety of the system, particularly for fault conditions. The type of grounding used determines the path of current for a ground fault and impacts the level of fault current a person is in danger of experiencing should contact be made with a conductor [5]. For datacenters, ETSI, the European Telecommunications Standards Institute, had published a European Standard document detailing the application of the two grounding methods for datacenters [77]. The choice of grounding configuration also depends on the availability of appropriate cables, busways, and connectors for the DC system, however the availability of components is often specific to the application.

TN-S Grounding Concept

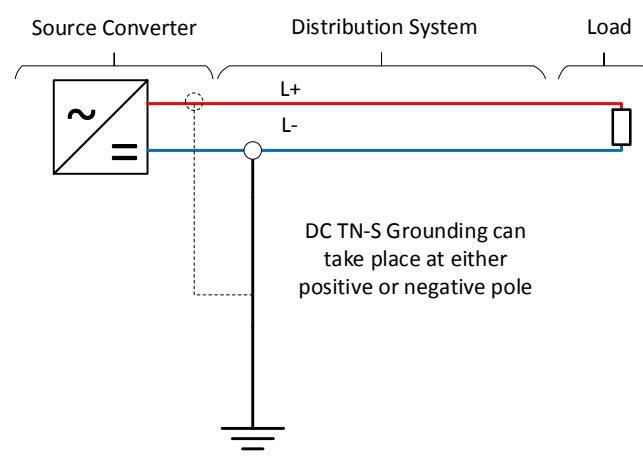

IT Grounding Concept

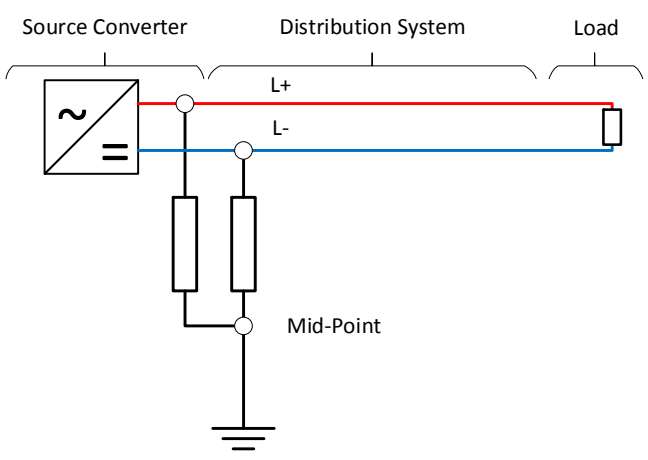

Figure 8. TN-S (left) and IT (right) Grounding Concepts for DC distribution systems.

\section{Conclusions}

DC architectures for electric power distribution systems and microgrids have been explored in literature with the goals of more efficiently serving modern loads and integrating distributed generation and storage. This paper provided examples from datacenters, residential power systems, telecommunications power systems, and renewable generation collector systems to motivate the discussion of DC distribution systems, but the literature cited also indicates a need for further standardization moving forward. While not directly addressed in this paper, other obstacles to the development, installation, and operation of DC distribution systems need to be addressed, including the lack of qualified and trained technicians with experience in DC distribution systems over $60 \mathrm{~V}$.

The main focus of this paper was the important consideration of power quality in the design of DC distribution systems. Power quality factors are well documented and studied in AC power systems, 
but many power quality questions have yet to be definitively addressed or studied for DC distribution systems. In particular, failures due to harmonic currents have been noted in literature in the DC link in variable frequency drives, and it is likely DC distribution systems that are not adequately designed with circulating currents due to nonlinear loads could experience similar failures. In particular, as research and system design moves towards in placing more variable frequency motor loads on DC systems, these authors would expect the harmonic issues to become more severe. The issues of inrush currents and available fault currents create an optimization trade-off in the sizing of EMI filter capacitors, unless soft-start circuits are implemented for energizing the filter capacitance. Further research and awareness in this tradeoff is important as DC system implementation moves forward. Lastly, the power quality and safety impacts of various grounding considerations are important considerations in the design and implementation of DC systems.

It is convenient to assume that DC distribution systems and microgrids will not have the same level of power quality problems that conventional AC systems do. However, DC designs do need to take into account power quality concerns such as those addressed in this paper, and while most or all of the issues have been addressed for particular cases in published literature like that referenced, significant work remains for standardization to be achieved for DC distribution systems in emerging areas of application like residential or commercial systems.

\section{Acknowledgments}

The research in sustainable wireless areas is supported by the National Science Foundation (NSF) under award \#CCF-1331788. Research in DC architecture design is supported by the Henry L. Hillman Foundation.

\section{Author Contributions}

Stephen Whaite performed the literature review on power quality in DC distribution systems and wrote the sections on power quality. Brandon Grainger researched and wrote the DC architecture sections on data centers, residential power distribution, and renewable generation collector systems. Alexis Kwasinski researched and wrote the architecture section on telecommunications power distributions. All authors contributed to the writing of the manuscript, and have read and approved the final manuscript.

\section{Conflicts of Interest}

The authors declare no conflict of interest.

\section{References}

1. Electric Power Research Institute (EPRI). DC Power Production, Delivery and Utilization; EPRI: Palo Alto, CA, USA, 2006.

2. Szpek, M.; Sonnenberg, B.J.; Lisy, S.M. 400VDC distribution architectures for central offices and data centers. In Proceedings of the 2014 IEEE 36th International Telecommunications Energy Conference (INTELEC), Vancouver, BC, Canada, 28 September-2 October 2014; pp. 1-6. 
3. Noritake, M.; Yuasa, K.; Takeda, T.; Hoshi, H.; Hirose, K. Demonstrative research on DC microgrids for office buildings. In Proceedings of the 2014 IEEE 36th International Telecommunications Energy Conference (INTELEC), Vancouver, BC, Canada, 28 September-2 October 2014; pp. 1-5.

4. Zhang, W.; Lee, F.C.; Huang, P.-Y. Energy management system control and experiment for future home. In Proceedings of the 2014 IEEE Energy Conversion Congress and Exposition (ECCE), Pittsburgh, PA, USA, 14-18 September 2014; pp. 3317-3324.

5. Engelen, K.; Shun, E.L.; Vermeyen, P.; Pardon, I.; D’hulst, R.; Driesen, J.; Belmans, R. The feasibility of small-scale residential DC distribution systems. In Proceedings of the IECON 2006-32nd Annual Conference on IEEE Industrial Electronics, Paris, France, 6-10 November 2006; pp. 2618-2623.

6. Ryu, M.-H.; Kim, H.-S.; Kim, J.-H.; Baek, J.-W.; Jung, J.-H. Test bed implementation of 380V DC distribution system using isolated bidirectional power converters. In Proceedings of the 2013 IEEE Energy Conversion Congress and Exposition, Denver, CO, USA, 15-19 September 2013; pp. 2948-2954.

7. Kwasinski, A.; Kwasinski, A. Operational aspects and power architecture design for a microgrid to increase the use of renewable energy in wireless communication networks. In Proceedings of the 2014 International Power Electronics Conference (IPEC-Hiroshima 2014-ECCE ASIA), Hiroshima, Japan, 18-21 May 2014; pp. 2649-2655.

8. Kwasinski, A.; Kwasinski, A. Role of energy storage in a microgrid for increased use of photovoltaic systems in wireless communication networks. In Proceedings of the 2014 IEEE 36th International Telecommunications Energy Conference (INTELEC), Vancouver, BC, Canada, 28 September-2 October 2014; pp. 1-8.

9. Electric Power Research Institute (EPRI). DPQ Executive Summary; EPRI: Palo Alto, CA, USA, 2003.

10. The Institute of Electrical and Electronics Engineers. Recommended Practices and Requirements for Harmonic Control in Electrical Power Systems; IEEE: Piscataway, NJ, USA, 1993; pp. 1-112.

11. Prousalidis, J.; Styvaktakis, E.; Kanellos, F.; Perros, S.; Sofras, E. Electric power supply quality in ship systems: An overview. Int. J. Ocean Syst. Manag. 2008, 1, 68-83.

12. West, E.G. Analysis of Harmonic Distortion in an Integrated Power System for Naval Applications; Massachusetts Institute of Technology: Cambridge, MA, USA, 2005.

13. Ericsen, T. Engineering "total electric ship". In Proceedings of the 2007 IEEE Petroleum and Chemical Industry Technical Conference, Calgary, AB, Canada, 17-19 September 2007; pp. 1-6.

14. Moir, I.; Seabridge, A. Aircraft Systems: Mechanical, Electrical and Avionics Subsystems Integration; John Wiley \& Sons: Hoboken, NJ, USA, 2011.

15. Emadi, A.; Rajashekara, K. Power electronics and motor drives in electric, hybrid electric, and plug-in hybrid electric vehicles. IEEE Trans. Ind. Electron. 2008, 55, 2237-2245.

16. Lee, Y.H.; Nasiri, A. Analysis and modeling of conductive EMI noise of power electronics converters in electric and hybrid electric vehicles. In Proceedings of the 2008 Twenty-Third Annual IEEE Applied Power Electronics Conference and Exposition, Austin, TX, USA, 24-28 February 2008; pp. 1952-1957. 
17. Uriarte, F.M.; Hebner, R.E.; Kwasinski, A.; Gattozzi, A.L.; Estes, H.B.; Anwar, A.; Cairoli, P.; Dougal, R.; Dougal, A.; Feng, X.; et. al. Technical cross-fertilization between terrestrial microgrids and ship power systems. In Proceedings of the ESRDC 10th Anniversary Meeting, Austin, TX, USA, 4-6 June 2012.

18. Masanet, E.R.; Brown, R.E.; Shehabi, A.; Koomey, J.G.; Nordman, B. Estimating the energy use and efficiency potential of U.S. data centers. Proc. IEEE 2011, 99, 1440-1453.

19. Candan, E.; Shenoy, P.S.; Pilawa-Podgurski, R.C.N. A series-stacked power delivery architecture with isolated differential power conversion for data centers. In Proceedings of the 2014 IEEE 36th International Telecommunications Energy Conference (INTELEC), Vancouver, BC, Canada, 28 September-2 October 2014; pp. 1-8.

20. Krein, P.T. A discussion of data center power challenges across the system. In Proceedings of the 2010 International Conference on Energy Aware Computing, Cairo, Egypt, 16-18 December 2010; pp. 1-3.

21. Kwasinski, A. Advanced power electronics enabled distribution architectures: Design, operation, and control. In Proceedings of the 8th International Conference on Power Electronics-ECCE Asia, Jeju, Korea, 30 May-3 June 2011; pp. 1484-1491.

22. Kwasinski, A.; Onwuchekwa, C.N. Dynamic behavior and stabilization of DC microgrids with instantaneous constant-power loads. IEEE Trans. Power Electron. 2011, 26, 822-834.

23. Salomonsson, D.; Soder, L.; Sannino, A. An adaptive control system for a DC microgrid for data centers. IEEE Trans. Ind. Appl. 2008, 44, 1910-1917.

24. Kwasinski, A. Analysis of electric power architectures to improve availability and efficiency of air conditioning systems. In Proceedings of the INTELEC 2008-2008 IEEE 30th International Telecommunications Energy Conference, San Diego, CA, USA, 14-18 September 2008; pp. 1-8.

25. Zhang, W.; Guo, B.; Xu, F.; Cui, Y.; Long, Y.; Wang, F.; Tolbert, L.M.; Blalock, B.J.; Costinett, D.J. Wide bandgap power devices based high efficiency power converters for data center application. In Proceedings of the 2014 IEEE Workshop on Wide Bandgap Power Devices and Applications, Knoxville, TN, USA, 13-15 October 2014; pp. 121-126.

26. Shenoy, P.S.; Krein, P.T. Differential power processing for DC systems. IEEE Trans. Power Electron. 2013, 28, 1795-1806.

27. Pratt, A.; Kumar, P.; Aldridge, T.V. Evaluation of 400V DC distribution in telco and data centers to improve energy efficiency. In Proceedings of the INTELEC 07-29th International Telecommunications Energy Conference, Rome, Italy, 30 September-4 October 2007; pp. 32-39.

28. Allen, W.; Natale, S.V. Achieving ultra-high system availability in a battery-less-48VDC power plant. In Proceedings of the 24th Annual International Telecommunications Energy Conference, Montréal, QC, Canada, 29 September-3 October 2002; pp. 287-294.

29. Inamori, J.; Hoshi, H.; Tanaka, T.; Babasaki, T.; Hirose, K. 380-VDC power distribution system for 4-MW-scale cloud facility. In Proceedings of the 2014 IEEE 36th International Telecommunications Energy Conference (INTELEC), Vancouver, BC, Canada, 28 September-2 October 2014; pp. 1-8.

30. Hirose, K. Consideration of voltage range of a 380 VDC distribution system for international standardization. In Proceedings of the 2013 35th International Telecommunications Energy Conference 'Smart Power and Efficiency' (INTELEC), Hamburg, Germany, 13-17 October 2013; pp. 1-6. 
31. AlLee, G.; Tschudi, W. Edison redux: $380 \mathrm{Vdc}$ brings reliability and efficiency to sustainable data centers. IEEE Power Energy Mag. 2012, 10, 50-59.

32. Marnay, C. On voltage standards for DC home microgrids energized by distributed sources. In Proceedings of the 7th International Power Electronics and Motion Control Conference, Harbin, China, 2-5 June 2012; Volume 3, pp. 2282-2286.

33. Patterson, B.T. DC, come home: DC microgrids and the birth of the "Enernet". IEEE Power Energy Mag. 2012, 10, 60-69.

34. Office of Electricity Delivery and Energy Reliability. Power Electronics Research and Development Program Plan; Office of Electricity Delivery and Energy Reliability: Washington, DC, USA, 2011; p. 21.

35. Lucia, O.; Cvetkovic, I.; Sarnago, H.; Boroyevich, D.; Mattavelli, P.; Lee, F.C. Design of home appliances for a DC-based nanogrid system: An induction range study case. IEEE J. Emerg. Sel. Top. Power Electron. 2013, 1, 315-326.

36. Thomas, B.A. Edison revisited: Impact of DC distribution on the cost of LED lighting and distributed generation. In Proceedings of the 2010 Twenty-Fifth Annual IEEE Applied Power Electronics Conference and Exposition (APEC), Palm Springs, CA, USA, 21-25 February 2010, 588-593.

37. Wunder, B.; Ott, L.; Szpek, M.; Boeke, U.; Weis, R. Energy efficient DC-grids for commercial buildings. In Proceedings of the 2014 IEEE 36th International Telecommunications Energy Conference (INTELEC), Vancouver, BC, Canada, 28 September-2 October 2014; pp. 1-8.

38. Thomas, B.A.; Azevedo, I.L.; Morgan, G. Edison revisited: Should we use DC circuits for lighting in commercial buildings? Energy Policy 2012, 45, 399-411.

39. Starke, M.; Tolbert, L.M.; Ozpineci, B. AC vs. DC distribution: A loss comparison. In Proceedings of the 2008 IEEE/PES Transmission and Distribution Conference and Exposition, Chicago, IL, USA, 21-24 April 2008; pp. 1-7.

40. Reed, G.F.; Grainger, B.M.; Sparacino, A.R. Ship to grid: Medium-voltage DC concepts in theory and practice. IEEE Power Energy Mag. 2012, 10, 70-79.

41. Guerrero, J.M.; Vasquez, J.C.; Matas, J.; de Vicuna, L.G.; Castilla, M. Hierarchical control of droop-controlled AC and DC microgrids-A general approach toward standardization. IEEE Trans. Ind. Electron. 2011, 58, 158-172.

42. Kwasinski, A. Identification of feasible topologies for multiple-input DC-DC converters. IEEE Trans. Power Electron. 2009, 24, 856-861.

43. Behjati, H.; Davoudi, A. A multiple-input multiple-output DC-DC converter. IEEE Trans. Ind. Appl. 2013, 49, 1464-1479.

44. Madhusoodhanan, S.; Tripathi, A.; Patel, D.; Mainali, K.; Bhattacharya, S. Stability analysis of the high voltage DC link between the FEC and DC-DC stage of a transformer-less intelligent power substation. In Proceedings of the 2014 IEEE Energy Conversion Congress and Exposition (ECCE), Pittsburgh, PA, USA, 14-18 September 2014; pp. 3702-3709.

45. De Doncker, R.W.A.A.; Divan, D.M.; Kheraluwala, M.H. A three-phase soft-switched high-power-density DC/DC converter for high-power applications. IEEE Trans. Ind. Appl. 1991, $27,63-73$. 
46. Kwasinski, A. Telecommunications outside plant power infrastructure: Past performance and technological alternatives for improved resilience to hurricanes. In Proceedings of the INTELEC 2009-31st International Telecommunications Energy Conference, Incheon, Korea, 18-22 October 2009; pp. 1-6.

47. Kwasinski, A.; Kwasinski, A. Increasing sustainability and resiliency of cellular networks infrastructure by harvesting renewable energy. IEEE Commun. Mag. 2015, 53, 110-116.

48. Meyer, C.; Hoing, M.; Peterson, A.; de Doncker, R.W. Control and design of DC grids for offshore wind farms. IEEE Trans. Ind. Appl. 2007, 43, 1475-1482.

49. Chen, W.; Huang, A.Q.; Li, C.; Wang, G.; Gu, W. Analysis and comparison of medium voltage high power DC/DC converters for offshore wind energy systems. IEEE Trans. Power Electron. 2014, 28, 2014-2023.

50. The Institute of Electrical and Electronics Engineers. IEEE Guide for Identifying and Improving Voltage Quality in Power Systems; IEEE: Piscataway, NJ, USA, 2011; pp. 1-70.

51. Electric Power Research Institute (EPRI). DPQ Report: Surveying Power Quality Levels on U.S. Distribution Systems; EPRI: Palo Alto, CA, USA, 2003.

52. Guerrero, J.M.; Loh, P.C.; Lee, T.-L.; Chandorkar, M. Advanced control architectures for intelligent microgrids-Part II: Power quality, energy storage, and AC/DC microgrids. IEEE Trans. Ind. Electron. 2013, 60, 1263-1270.

53. Siemens AG. Microgrids; Siemens AG: Berlin, Germany, 2011.

54. Cividino, L. Power factor, harmonic distortion; causes, effects and considerations. In Proceedings of the Fourteenth International Telecommunications Energy Conference-INTELEC'92, Washington, DC, USA, 4-8 October 1992; pp. 506-513.

55. Grady, W.M.; Gilleskie, R.J. Harmonics and how they relate to power factor. In Proceedings of the EPRI Power Quality Issues \& Opportunities Conference (PQA'93), San Diego, CA, USA, 16-19 November 1993; pp. 1-8.

56. Li, Y.W.; He, J. Distribution system harmonic compensation methods: An overview of DG-interfacing inverters. IEEE Ind. Electron. Mag. 2014, 8, 18-31.

57. Electric Power Research Institute (EPRI). Distribution System Power Quality Assessment Phase II: Voltage Sag and Interruption Analysis; EPRI: Palo Alto, CA, USA, 2003; Volume 3.

58. Zhang, R.; Lee, F.C.; Boroyevich, D.; Liu, C.; Chen, L. AC load conditioner and DC bus conditioner for a DC distribution power system. In 2000 IEEE 31st Annual Power Electronics Specialists Conference. Conference Proceedings (Cat. No.00CH37018); IEEE: Piscataway, NJ, USA, 2000; Volume 1, pp. 107-112.

59. Xu, Z.; Huang, Y.; Li, X.; Wang, F. DC harmonic current calculation for HVDC systems based on the classical transmission line model. In Proceedings of the 2010 International Conference on Power System Technology, Hangzhou, China, 24-28 October 2010; pp. 1-5.

60. Graham, A.D. The importance of a DC side harmonic study for a DC distribution system. In Proceedings of the 6th IET International Conference on Power Electronics, Machines and Drives (PEMD 2012), Bristol, UK, 27-29 March 2012; pp. 1-5. 
61. Zhang, H.; Wheeler, N.; Grant, D. Switching harmonics in the DC link current in a PWM AC-DC-AC converter. In Proceedings of the IAS '95. Conference Record of the 1995 IEEE Industry Applications Conference Thirtieth IAS Annual Meeting, Orlando, FL, USA, 8-12 October 1995; Volume 3, pp. 2649-2655.

62. Bierhoff, M.H.; Fuchs, F.W. DC-link harmonics of three-phase voltage-source converters influenced by the pulsewidth-modulation strategy-An analysis. IEEE Trans. Ind. Electron. 2008, 55, 2085-2092.

63. McGrath, B.P.; Holmes, D.G. A general analytical method for calculating inverter DC-link current harmonics. IEEE Trans. Ind. Appl. 2009, 45, 1851-1859.

64. Browne, T.J.; Browne, N.R. Power quality considerations for utilities supplying residential DC installations. In Proceedings of the 2008 13th International Conference on Harmonics and Quality of Power, Wollongong, Australia, 28 September-1 October 2008; pp. 1-5.

65. Blooming, T.M.; Carnovale, D.J. Application of IEEE STD 519-1992 Harmonic Limits. In Proceedings of the Conference Record of Annual on Pulp and Paper Industry Technical Conference, 2006, Appleton, WI, USA, 18-23 June 2006; pp. 1-9.

66. Hoshi, H.; Tanaka, T.; Noritake, M.; Ushirokawa, T.; Hirose, K.; Mino, M. Consideration of inrush current on DC distribution system. In Proceedings of the 2012 IEEE 34th International Telecommunications Energy Conference (INTELEC), Scottsdale, AZ, USA, 30 September-4 October 2012; pp. 1-4.

67. Asakimori, K.; Murai, K.; Tanaka, T.; Babasaki, T. Effect of inrush current flowing into EMI filter on the operation of ICT equipment in HVDC system. In Proceedings of the 2014 IEEE 36th International Telecommunications Energy Conference (INTELEC), Vancouver, BC, Canada, 28 September-2 October 2014; pp. 1-5.

68. Davies, B. Analysis of inrush currents for DC powered IT equipment. In Proceedings of the 2011 IEEE 33rd International Telecommunications Energy Conference (INTELEC), Amsterdam, The Netherlands, 9-13 October 2011; pp. 1-4.

69. Iino, T.; Hirose, K.; Noritake, M.; Nakamura, A.; Kiryu, K.; Sekikawa, J. Characteristics of 400 V dc plug and socket-outlet for DC distribution systems. In Proceedings of the 2012 International Conference on Renewable Energy Research and Applications (ICRERA), Nagasaki, Japan, 11-14 November 2012; pp. 1-6.

70. Aoki, T.; Yamasaki, M.; Takeda, T.; Tanaka, T.; Harada, H.; Nakamura, K. Guidelines for power-supply systems for datacom equipment in NTT. In Proceedings of the 24th Annual International Telecommunications Energy Conference, Montréal, QC, Canada, 29 September-3 October 2002; pp. 134-139.

71. Lazaroiu, G.C.; Tironi, E.; Popescu, M.O.; Ghita, O.; Dumbrava, V. Transient analysis of DG interfaced low voltage dc system. In Proceedings of 14th International Conference on Harmonics and Quality of Power-ICHQP 2010, Bergamo, Italy, 26-29 September 2010; pp. 1-6.

72. Giancaterino, J.A. DC-DC converter plants and their ability to clear distribution fuses. In Proceedings of the 16th International Telecommunications Energy Conference, 1994, INTELEC'94, Vancouver, BC, Canada, 30 October-3 November 1994; pp. 315-320. 
73. Estes, H.B.; Kwasinski, A.; Hebner, R.E.; Uriarte, F.M.; Gattozzi, A.L. Open series fault comparison in AC \& DC micro-grid architectures. In Proceedings of the 2011 IEEE 33rd International Telecommunications Energy Conference (INTELEC), Amsterdam, The Netherlands, 9-13 October 2011; pp. 1-6.

74. Uriarte, F.M.; Gattozzi, A.L.; Herbst, J.D.; Estes, H.B.; Hotz, T.J.; Kwasinski, A.; Hebner, R.E. A DC arc model for series faults in low voltage microgrids. IEEE Trans. Smart Grid 2012, 3, 2063-2070.

75. Salomonsson, D.; Soder, L.; Sannino, A. Protection of low-voltage DC microgrids. IEEE Trans. Power Deliv. 2009, 24, 1045-1053.

76. Cuzner, R.M.; Venkataramanan, G. The Status of DC Micro-Grid Protection. In Proceedings of the 2008 IEEE Industry Applications Society Annual Meeting, Edmonton, AB, Canada, 5-9 October 2008; pp. 1-8.

77. European Telecommunications Standards Institute (ETSI). ETSI EN 301 605-Environmental Engineering (EE); Earthing and Bonding of 400 VDC Data and Telecom (ICT) Equipment; ETSI: Nice, France, 2011; Volume 1, pp. 1-85.

(C) 2015 by the authors; licensee MDPI, Basel, Switzerland. This article is an open access article distributed under the terms and conditions of the Creative Commons Attribution license (http://creativecommons.org/licenses/by/4.0/). 